\title{
Confidence and motivation to help those with a mental health problem: experiences from a study of nursing students completing mental health first aid (MHFA) training
}

\author{
Gemma Crawford ${ }^{*}$ id and Sharyn Burns
}

\begin{abstract}
Background: Those studying nursing are at greater risk for developing mental health problems than other tertiary students. Mental Health First Aid (MHFA) training may assist students to support peers and build mental health literacy. Understanding motivation to participate in training can identify factors influencing uptake and completion. This paper explores motivators for university nursing students to participate in MHFA training and uses previous experience and confidence in assisting someone with a mental health problem to triangulate data.
\end{abstract}

Method: A randomised controlled trial was employed to measure the impact of the course for nursing students at a large Western Australian university. An online survey was administered prior to MHFA training with undergraduate nursing students $(n=140)$. Thematic analysis of open-ended questions explores motivators to participate and help provided to an individual. Baseline frequencies describe demographics, confidence in helping and exposure to someone with a mental health problem. A Chi Square test compared confidence in helping and exposure to someone with a mental health problem.

Results: More than half of participants reported contact with individuals experiencing mental health problems (55\%; $n=77)$; approximately a third (35.8\%) reported limited confidence to assist. Those in previous contact with someone with a mental health problem $(71.5 \% ; n=55)$ were significantly more likely to feel confident in helping $(p=0.044)$. Mental health literacy, helping others, career and experiences were described as training motivators.

Conclusion: Exploiting motivators, both intrinsic and extrinsic may increase MHFA training uptake and completion. Tertiary institutions would benefit from policy to embed MHFA training into nursing degrees. The training may have utility for university degrees more broadly.

Trial registration: Australian New Zealand Clinical Trials Registry; ACTRN12614000861651. Registered 11 August 2014 (retrospectively registered).

Keywords: Mental health first aid, Mental health, Universities, Nursing students, Prevention, Early intervention, Motivators, Training, Education, Mental health literacy

\footnotetext{
* Correspondence: g.crawford@curtin.edu.au

Collaboration for Evidence, Research and Impact in Public Health, School of Public Health, Faculty of Health Sciences, Curtin University, GPO Box U1987,

Perth 6845, Western Australia
}

(c) The Author(s). 2020 Open Access This article is licensed under a Creative Commons Attribution 4.0 International License, which permits use, sharing, adaptation, distribution and reproduction in any medium or format, as long as you give appropriate credit to the original author(s) and the source, provide a link to the Creative Commons licence, and indicate if changes were made. The images or other third party material in this article are included in the article's Creative Commons licence, unless indicated otherwise in a credit line to the material. If material is not included in the article's Creative Commons licence and your intended use is not permitted by statutory regulation or exceeds the permitted use, you will need to obtain permission directly from the copyright holder. To view a copy of this licence, visit http://creativecommons.org/licenses/by/4.0/. The Creative Commons Public Domain Dedication waiver (http://creativecommons.org/publicdomain/zero/1.0/) applies to the data made available in this article, unless otherwise stated in a credit line to the data. 


\section{Background}

Each year, around $20 \%$ of Australians aged 16 to 85 will experience a mental health problem [1]. Of those affected, $75 \%$ will experience their first episode by age 25 [1]. Despite high prevalence and early onset, help seeking remains low [2-4] and mental health literacy remains inadequate $[5,6]$. Improving community mental health literacy may encourage professional help seeking, reduce stigma, and increase support networks [7-11].

Internationally, poor mental health and subsequent impacts is recognised as a concern for tertiary institutions [12-15]. Studies suggest tertiary students have an increased likelihood of experiencing psychological distress compared to non-students their age [16-19]. Further, research has shown young people do not seek professional help for their mental health problems [14, 20], with students more likely to confide in close friends or family or choose self-help strategies instead of counselling [20,21]. Mental health problems among university students can lead to negative impacts on academic success including cessation of studies, high levels of absenteeism and failure, and reduced productivity [12, 22-25]. Attending university may increase levels of distress for many young people, consequently appropriate support is required to throughout studies and in the transition to the workforce [26-28].

The demands of studying specific courses including nursing have been associated with stressors that can result in additional distress as students advance through the course and increase risks for developing mental health problems [27-31]. An Australian study of undergraduate nursing students $(n=431)$ found exhaustion and stress levels increased each year [32]. Research by Evans and Kelly support these findings, suggesting additional challenges for nursing students including academic workload, theory-practice gap, difficulties and realities of clinical placement, leading to feeling overwhelmed and a range of short term coping mechanisms to deal with exhaustion and stress [33].

In addition to personal mental health risks, poor levels of mental health literacy are found amongst nursing students in the formative component of their degrees [34]. Ongoing educational training has been associated with enhanced positive attitudes among nursing students towards the mental health sector [35]. This is critical as in Australia, nurses represent around half the mental health workforce [36-38].

Mental Health First Aid (MHFA) is a training course, facilitating skills to assist those experiencing a mental health problem or mental health crisis $[10,39]$. The course is designed to build mental health literacy, reducing stigma and discrimination towards mental health and providing direction for supportive actions $[4,40,41]$. Since the program's inception, extensive evaluation has consistently suggested a range of participation benefits. A systematic review of research related to MHFA training concluded that in all studies, MHFA training demonstrated increased mental health awareness and knowledge amongst participants [42]. Other positive outcomes included: improved recognition of mental illnesses [27, 42-47]; reduced stigmatising attitudes $[9,27,39,42-44,47-49]$ and decreased social distance $[27,46,47,49,50]$. Additionally, probability of recommending professional help increased [39, 42, 46, $49,50]$ and participants developed greater confidence to assist individuals experiencing a mental health problem [9, $27,39,43,44,46,48-50]$. Importantly, these outcomes have been maintained after course completion $[39,51]$.

In 2012, MHFA Australia commenced offering tailored courses to nursing students as part of an initiative to train 'frontline workers' [52]. The training aimed to benefit personal mental health and provide knowledge and skills to be used with peers and other adults. While the stated aim of the training was not mental health training [29], it may be that professional development is a motivation for many nursing students to participate.

Understanding motivation is important to identify factors that may influence why individuals choose to complete the course. Motivation can be described as either intrinsic (e.g. perceived internal and personal rewards for completing a task or action, such as increased knowledge or sense of accomplishment or self-worth) or extrinsic (e.g. external rewards, such as receiving recognition or good marks or avoiding punishment) [53, 54].

Studies suggest that despite the emphasis on external recognition in many institutions, intrinsic factors are often a key motivator for students studying at university $[53,55]$. Intrinsic motivation is seen as having meaningful and positive cognitive engagement with an individual's learning [53]. The ability to link current course work to future benefits and long term goals has been found a highly motivating, intrinsic factor [55] for high school or university students $[56,57]$ and may influence why individuals complete extracurricular courses.

Accordingly, MHFA training may provide a useful addition to curricula $[45,58,59]$ to assist undergraduate nursing students to meet the stated aim of the course to increase knowledge and skills relating to mental health problems, reduce stigma towards individuals or peers with mental health problems $[28,29]$ and support peers. However, students may also be motivated to take part in MHFA training due to additional benefits consistent with those described above relating to community contribution and career advancement.

This study was part of a broader research project to determine the impact of Mental Health First Aid training on pre-service university nursing students and the factors influencing participation [28]. The broader study measured outcomes including: knowledge, recognition of depression, first aid intentions and stigmatising attitudes (published 
elsewhere) [60]. The aim of the research presented in this paper was to describe the participant profile and explore personal motivation of first year nursing students to participate in MHFA training. Open-ended questions explore motivators for participation and data are triangulated with demographics, previous experience and confidence in assisting someone with a mental health problem. Findings will inform Mental Health First Aid and other training interventions for nursing students in a university setting.

\section{Methods}

The broader study employed a pragmatic, waitlisted, randomised controlled trial (methods described briefly below and in detail elsewhere $[28,60])$. For the present study, survey data collected at baseline (quantitative and qualitative) was used to explore pre-service nursing student motivators for completing MHFA training and to investigate key demographics, previous mental health training, experience in helping someone with a mental health problem and perceived confidence to help prior to completing the training.

\section{Procedure}

Participants were eligible to participate if they were undergraduate, first-year nursing students aged 18 years and over enrolled via internal teaching mode at a large Australian university. A total of 200 nursing students registered for the intervention. After initial drop out and removal of ineligible students $(n=19)$ (those who did not meet the eligibility described above), 181 students were randomised into either the intervention $(n=92)$ or control $(n=89)$ group. The intervention group participated in tailored MHFA training [28]. The control group received no intervention during the data collection period, but was waitlisted to be offered online MHFA training on intervention conclusion. Baseline quantitative and qualitative data were collected from intervention and control group participants via a self-complete online survey administered via student email 1 week prior to the commencement of the training course. The sample and procedure as it relates to the CONSORT guidelines is described in detail elsewhere [28, 60]. Ethical approval was granted by the Curtin University $\mathrm{Hu}-$ man Research Ethics Committee (SPH-74-2013). This trial was registered with the Australian New Zealand Clinical Trials Registry: ACTRN12614000861651.

\section{Survey}

The survey was based on previous questionnaires developed to measure mental health literacy, confidence, MHFA intentions and stigmatising attitudes [27, 43, 44, $46,47,50,61,62]$. The following items were collected at baseline and are described in this paper: previous completion of MHFA or other training, units or placements; motivation for undertaking MHFA training; confidence to assist someone with a mental health problem; contact with someone with a mental health problem; and previous experience in providing help to someone with a mental health problem. Table 1 describes the items included in the survey and where they have been reported. Instrument development is described in detail elsewhere $[28,60]$.

\section{Data analysis}

Frequencies were computed to describe demographics, confidence in helping and exposure to someone with a mental health problem. Proportions were compared for confidence in helping and exposure to someone with a mental health problem using a Chi Square test. Statistical significance was determined at $p<0.05$. Quantitative data were analysed using SPSS version 22 [65]. Qualitative data were collected via open-ended responses to questions in the online survey. Motivators for participation and help provided to an individual with a mental health problem were explored via Braun and Clarke's broad approach to thematic analysis [66] and consistent with thematic analysis in other qualitative studies by the research team [67-70]. Quantitative data were triangulated with qualitative data to enhance credibility. Thematic analysis incorporated the following steps: 1) transcribing and becoming familiar with the data which involved reading and re-reading transcripts; 2) generating a broad list of initial codes by examining words and phrases of each response; 3 ) collating codes into potential themes; 4) reviewing themes and creating a thematic map; 5) defining and refining core themes and subthemes; here mental health literacy was positioned as the central, underpinning theme 6) selecting exemplar quotations for inclusion in analysis and relating analysis to research aims. Both members of the research team independently coded data. Examination of data by multiple researchers reduced bias and improved confirmability of the study [71]. Qualitative data was managed using QSR International's NVivo 11 Software [72].

\section{Results \\ Group characteristics}

Of the 140 participants, $83.6 \%(n=117)$ were female. Approximately three quarters $(75.7 \%, n=106)$ of the sample were aged 18 to 24 years. The majority $(97.1 \%$, $n=136)$ had no previous mental health training prior to the course. Demographics are summarised in Table 2.

\section{Previous mental health training}

Eleven participants had undertaken some form of prior training in mental health. Three participants had previously undertaken mental health training/education in a workplace environment. Six participants had undertaken previous mental health units in their nursing degree; 
Table 1 Survey Items

\begin{tabular}{ll}
\hline Survey Domains & Items \\
\hline Demographics & Gender, age, student status (domestic/international), enrolment status (full time/part time)
\end{tabular}

(collected at baseline)

Previous experience with mental health (collected at baseline and reported here)

\section{Motivation for undertaking MHFA training} (collected at baseline and reported here)

\section{Existing confidence to assist someone with a mental health problem}

(collected at baseline and reported here)

Previous contact with someone with a mental health problem

(collected at baseline and reported here)

Previous experience in providing help to someone with a mental health problem

(collected at baseline and reported here)

\section{Mental health knowledge}

(collected at all timepoints and reported previously)

\section{Confidence and Intentions}

(collected at all timepoints and reported previously)

Stigma

(collected at all timepoints and reported previously)
To determine familiarity with course content and previous mental health skills and knowledge, participants were asked if they had previously completed MHFA training, other education or training in mental health, mental health units in their current course of study or a mental health related clinical placement during current course of study. Responses were dichotomised to 'yes' or 'no'. Participants who had completed other training, units or relevant placements, were asked to provide details including the provider and the year completed.

Assessed using an open ended question was used to explore motivation for completing the MHFA course $[46,50,63,64]$.

Assessed by asking participants if they felt confident in helping someone with a mental health problem. A five point Likert scale was provided with responses ranging from 'not at all' to 'extremely confident' $[46,50]$.

To determine exposure to individuals with mental health problems participants were asked if they had had contact with someone with a mental health problem during the last six months. Responses included 'yes', 'no' and 'don't know'.

Two questions asked of those who answered yes to previous contact.

1. Open ended question which asked how many people with a mental health problem they had contact with during this period. Coded to a few (1-3), some (4-9) and many (10 or more).

2. The second question asked if they offered any help. Responses included 'not at all', 'a little', 'some' and 'a lot'. These questions were followed with a qualitative question regarding what type of help was provided. These questions have been used in previous evaluations of MHFA training $[46,50]$. Responses were coded against 10 broad categories with one point given for each response provided using the scoring described by Kelly and colleagues [9].

Knowledge was assessed using 20 true or false statements adapted from previously validated MHFA research.

Recognition of depression was assessed using a specific vignette about "John" and an open ended question "what, if anything is wrong with John?" which has been used in previous research.

Confidence was assessed by asking participants to rate their confidence to help 'John'. Responses included a five point Likert scale ranging from: don't know to very confident. This measure has been used in previous MHFA research.

Mental health first aid intentions were assessed using an open-ended question "Imagine John is someone you have known for a long time and care about. You want to help him. What would you do? Responses were scored using a previously used system in other MHFA studies and based on the ALGEE action plan which is a key focus of MHFA.

Stigmatising attitudes including social distance were measured. Stigmatising attitudes were assessed using a seven item scale adapted from the validated Depression Stigma Scale to measure personal and perceived stigma. Social distance was measured by a scale adapted from the validated Social Distance Scale. Both have been used in other MHFA studies. three were specific mental health units, while the others included mental health as a component. Two participants had undertaken practical placements in a mental health facility. These placements were in nursing homes and ranged from 6 days to 3 weeks.

\section{Confidence}

Prior to course participation, confidence in helping someone with a mental health problem varied. Around a third of participants reported being 'quite' or 'extremely' $(30.6 \% ; n=40)$; confident while a further third reported having 'little' or 'no' confidence $(35.8 \% ; n=$ 50 ) in helping someone with a mental health problem (see Table 1).

\section{Previous experiences with mental health}

Over half $(55 \% ; n=77)$ of participants reported direct contact with an individual experiencing a mental health issue within the preceding 6 months while $32.1 \%$ reported no contact and around 13\% were unsure if they had come into contact with someone in the preceding 6 months. Two-thirds of these participants indicated they had had contact with a few $(62.3 \% ; n=48)$ people with a mental health problem during this time period. Participants who had contact with someone with a mental health problem were significantly more likely to feel confident in helping compared to those who reported no contact ( $\mathrm{x} 2=12.952 ; \mathrm{df}=6 ; p=0.044)$. Of those who had had contact the majority $(71.5 \% ; n=55)$ felt moderately to extremely confident in helping compared to 
Table 2 Participant characteristics and previous mental health experience

\begin{tabular}{ll}
\hline Demographic & Total (\%) \\
\hline Gender & $23(16.4)$ \\
Male & $117(83.6)$ \\
Female & \\
Age & $106(75.7)$ \\
$18-24$ & $16(11.4)$ \\
$25-30$ & $7(5)$ \\
$31-35$ & $3(2.1)$ \\
$36-40$ & $8(5.7)$ \\
$41+$ &
\end{tabular}

Mental health units completed during degree

Yes $6(4.3)$

No 134 (95.7)

Practical mental health facility placement during degree

Yes 2 (1.4)

No 138 (98.6)

Confidence in helping someone with a mental health problem

$\begin{array}{ll}\text { Not at all } & 11(7.9) \\ \text { A little bit } & 39(27.9) \\ \text { Moderately } & 50(35.7) \\ \text { Quite a bit } & 33(23.6) \\ \text { Extremely } & 7(5)\end{array}$

Contact with someone with a mental health problem (past 6 months)

$\begin{array}{ll}\text { Yes } & 77(55) \\ \text { No } & 45(32.1) \\ \text { Don't know } & 18(12.9)\end{array}$

Don't know 18 (12.9)

Number of people in contact with a mental health problem

$\begin{array}{ll}\text { A few (1-3) } & 48(62.3) \\ \text { Some (4-9) } & 18(23.4) \\ \text { Many (10+) } & 11(14.3)\end{array}$

Support for someone with a mental health problem (if contact) $(n=77)$

\begin{tabular}{ll} 
Not at all & $3(3.9)$ \\
A little & $26(33.8)$ \\
Some & $26(33.8)$ \\
A lot & $22(26.8)$ \\
\hline
\end{tabular}

$57.8 \%(n=26)$ of those who had not come into contact with someone with a mental health problem.

\section{Previous type of help offered}

Of the 77 participants who reported direct contact with an individual experiencing a mental health problem, almost all had attempted to offer some help. The majority $(67.6 \% ; n=52)$ had offered 'a little' or 'some' help.
Of those reporting help across ten broad categories (see Table 3$)$, just over three quarters $(n=58)$ provided a response in the "Other" category such as: "Assisting them on public transport" and "Offering friendship and help with English." Helping consistent with the nine categories (below) were broadly: "spent time listening to their problems" (50.7\%; $n=39)$; "recommended they seek professional help" $(14 \% ; n=11)$ or "gave them information about the problem" (11.7\%; $n=9)$. The following quote highlights these types of help:

"I've said they can talk to me, referred them to counselling (headspace, kids' helpline, lifeline etc), offered them assistance when they need help, asked to take them out to get their mind off things ..."

Around two in five participants $(38.9 \% ; n=30)$ had provided help across two categories. Just under half (44.1\%; $n=34$ ) had provided help in only one category while just over $10 \%$ had provided assistance across three categories (13\%; $n=10)$. Few participants had offered help across four $(2.6 \% ; n=2)$ or five $(1.3 \% ; n=1)$ categories.

\section{Motivators to complete MHFA training}

Motivators for completing MHFA training were described through the four interrelated key themes of mental health literacy (knowledge, confidence and skills), helping others (described in relation to those who may be experiencing a mental health problem or crisis), career (improved skills or advancement) and experiences (described in relation to personal experiences of family, friends, peers and own mental health) (see Fig. 1 below).

Improving mental health literacy was an underlying motivator that was strongly linked to all themes. Helping others was linked to career while experiences influenced the desire to help others, and for some, motivated career choices.

Table 3 Ten categories of help offered

\begin{tabular}{ll}
\hline Category of help offered & Total (\%) \\
\hline 1. Spent time listening to their problem & $39(50.64)$ \\
2. Helped to calm them down & $4(5.19)$ \\
3. Talked to them about suicidal thoughts & $1(1.29)$ \\
4. Recommended they seek professional help & $11(14.28)$ \\
5. Recommended self-help strategies & $5(6.49)$ \\
6. Gave them information about their problem & $9(11.68)$ \\
7. Gave them information about local services & $3(3.89)$ \\
8. Made an appointment for them with services & $4(5.19)$ \\
9. Referred them to books or websites about their problem & $0(0)$ \\
10. Other & $58(75.32)$ \\
\hline
\end{tabular}




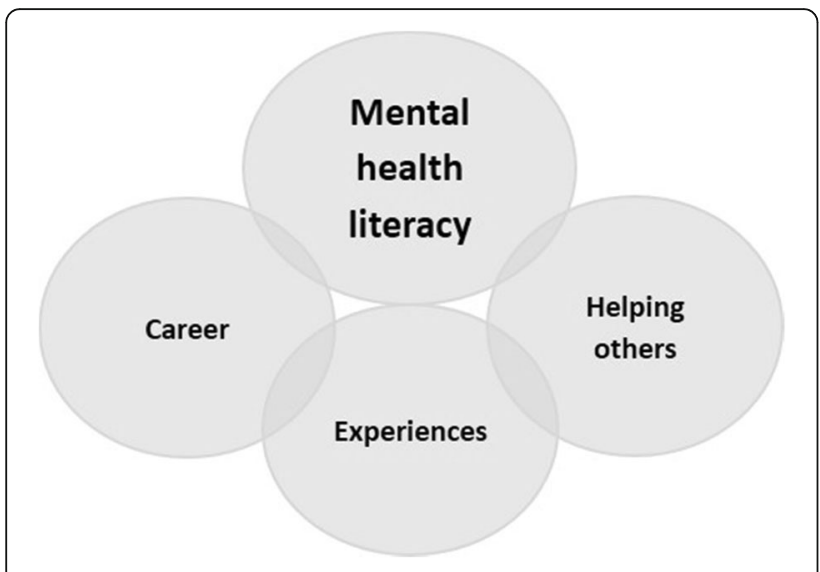

Fig. 1 Motivation to participate in Mental Health First Aid

The majority of participants described wanting to improve their mental health knowledge, skills and confidence (mental health literacy). Many of these comments reflected a desire to improve aspects of mental health literacy as they felt this would enhance their career as a nurse (career) but would also provide useful skills for everyday life (helping others). The importance of the need to enhance skills for their career and to help others generally is highlighted by the following:

"I believe dealing with mental illnesses will be a major part of my career as a nurse. Not only with my patients but also with the people around me in life and even within my family and close relationships. This course will help me to understand metal health better and teach me how to deal with certain situations and circumstances and how I can best offer myself to help those people."

While many of the comments reflected an initial intrinsic desire to enhance skills so they were more competitive in the workforce, or to complete voluntary hours as part of their degree, participants also reflected on the importance of the course in enhancing skills with a more extrinsic motivation. Some participants identified a lack of confidence in working with and being around people with mental health issues. Others identified the importance of the course in improving their skills in working with people with mental health problems, both in a professional situation and in everyday life. The participant statement: "To improve myself as a person and be a better health professional" provides a succinct representation of much of the discussion. The relationship between the career, mental health literacy and helping others themes is highlighted by the following:

"It's a great opportunity for further education. I think that having a recognised certificate will help set myself apart from others when applying for graduate positions. I also lack confidence when dealing with mental health so an early insight will be helpful."

The initial motivation of completing voluntary hours as part of their degree was expressed by some participants, however all participants who discussed the benefit of completing the course for volunteer hours also recognised the benefits of the course in terms of enhancing mental health literacy. Few participants identified that the course was free and that this was a motivator for participation:

"My motivation originally was to gain a few hours for my clinical log for [my unit] but since I have read more about this course and I feel it will benefit my skills when I become a nurse."

Helping others was a strong motivator for participants to complete this course. While some participants discussed the need to enhance mental health literacy to enhance their career, others expressed a desire to enhance skills to help others who may be suffering a mental health problem or crisis, for example:

"The idea that I will be in a position to help someone in a mental health crisis and be able to improve my skills."

While some respondents who discussed helping others referred to helping people generally, the theme of experiences linked closely to the need to help. Participants reflected on their own personal experiences of family, friends, peers and their own mental health problems and the desire to learn more about mental health problems and to enhance skills in dealing with issues. A few participants, typified by the following quote, discussed their passion for mental health which had developed as a result of personal experiences:

"I have an extreme passion and interest in mental health, and feel this is from growing up with a family member who has lived a life with mental health issues. I want to learn more about how to help them."

Others expressed a desire to better understand mental health and to help friends and peers who were experiencing mental health problems:

"To be able to help someone with a mental illness, to better understand them as I have had a few friends suffer severe depression and felt there wasn't anything I could do to help." 
A number of participants reflected on their own experiences of poor mental health which generated a desire to help others, for example, "I have my own mental health issues and would like to help others". Some reflected that even though they had personally experienced mental health problems they lacked knowledge:

"In the past I have been through some mental illnesses and so my main motivation for completing the Mental Health First Aid course is so I can gain more knowledge about signs and symptoms of most mental illnesses, so I can help them out as soon as I can before professional treatment is received or the crisis resolves."

\section{Discussion}

This paper explored motivation for nursing students to participate in tailored MHFA training. To better understand participant characteristics, the research measured levels of pre-training past experience and confidence relating to assisting someone with a mental health problem. Four interrelated themes including mental health literacy; helping others; career; and experiences emerged to understand motivators to participation in the training.

The majority of participants had not previously participated in any mental health training, education or placements and articulated a desire to enhance their mental health literacy., Consistent with the themes of helping others and experiences more than half reported direct contact with an individual experiencing a mental health issue within the previous 6 months. Those in previous contact with an individual with a mental health problem were significantly more likely to feel confident in helping compared to those who reported no contact. This higher level of confidence may be due to the nursing specific sample who have had some opportunity to put mental health knowledge in to practice [58], however is also consistent with findings in other MHFA studies relating to nursing students $[27,45,58]$, other health disciplines $[47,73]$ and broader university studies [74].

Of those who reported contact with an individual experiencing a mental health problem almost all had attempted to offer some form of help. Around half of participants specifically indicated that they had "spent time listening to their problems". This finding is consistent with previous MHFA research, specifically a randomised controlled trial which found at 2 year follow up the most commonly reported type of help offered was "listening non-judgementally" [75]. Participants discussed their desire for enhanced mental health literacy to enable them to better help others. Findings suggest those with a little previous experience may be motivated to attend training in recognition of the need to enhance their mental health first aid skills.
Themes presented in this study are consistent with those in other studies that describe participant motivation to take part in MHFA training. The literature suggests that motivation to participation may be due to work related reasons [46, 50, 63, 64], knowing someone close who had or was experiencing a mental health problem [46, 50], personal mental health $[46,50]$, because they believed it their duty to learn the appropriate skills $[46,50,63]$ or for general knowledge $[46,50,63$, 64]. Additionally, a study conducted among MHFA instructors suggested that personal experiences, working in mental health and volunteering were motivators for completing training [76]. It has been posited that recognition of the need to increase confidence may be another motivator for completing the course [30].

Themes are also consistent with the broader historical literature, such as work by Murphy and colleagues [77] citing a range of studies [78-81] highlighting influential factors in motivating participation in continuing professional development including: personal motivational orientation, improvement of professional knowledge and skills or aspirations for increased professional competence or promotion, and personal growth.

Our research suggests both intrinsic and extrinsic reasons for participation, with interrelated themes highlighting the synergies between both. Mathieu and Martineau [82] suggest several types of training participation motivation. This includes the intrinsic like-'motivation to learn' (i.e aspiration to learn content impacts on how much an individual learns during training) and extrinsic like-'motivation through expectation' (i.e. expectancy that putting in effort during training will result in skills and knowledge leading to valuable outcomes).

\section{Implications}

We suggest several implications for policy and practice. Happell and colleagues [58] suggest that availability of MHFA training should not negate the need for quality, mental health content in nursing university degrees. However, given the importance of ongoing professional development and reported negative attitudes towards mental health nursing as a career choice [35], implementation of MHFA training early in nursing degrees may contribute to improving desirability of mental health nursing as a future career [59]. This is an additional benefit to ensuring nursing students enhance mental health literacy early in their degree and regardless of the field of nursing that they pursue. Accordingly universities should consider embedding training as a component of courses for all undergraduate nursing students to enhance self and peer support and develop knowledge and confidence for the real world both professionally and personally [45]. Our training indicated the efficacy of delivery in a large, first-year unit with relatively 
limited resourcing, suggesting it may be a model that has utility for nursing and for health sciences more broadly. Establishing a community of practice of MHFA trained staff and students also has the added benefit of providing peer support to students for present or emerging mental health problems during university study.

The opportunity to better gauge participant motivation and experience prior to training may be useful for academics delivering such training with preservice nursing students. Individuals motivated to learn are also likely to be motivated to apply acquired skills [82], which is critical if knowledge is to be translated into practice in the workplace and more broadly. Seeking ways to appeal to intrinsic motivation to learn in promotion of training and participation may be valuable by focusing on knowledge and accomplishment [54]. This is an important consideration given findings suggest that intrinsic motivation strongly relates to performance and productivity for adults in the workforce [83]. Linking participation to course learning outcomes and providing credit for participation may be a strategy for consideration.

Consideration of intrinsic motivation can be balanced with appealing to extrinsic motivation. Recognition and reward schemes for MHFA trained staff and students may contribute to motivation to participate and to ensure ongoing currency of knowledge and skills relating to mental health literacy. This may include, developing rewards for course completion (log hours etc) or for performance (such as receiving accreditation that can be added to job readiness skills, making the student more desirable for employment) [84]. For those motivated by the desire to help others, providing opportunities to practice their newly acquired skills by taking on roles as peer champions or mentors within the university environment may be beneficial.

\section{Limitations}

Female participants were overrepresented in this study though this is consistent with the Australian nursing workforce profile [85]. Participants in this study are not representative of the general population. Nursing students likely have better mental health literacy than the general population meaning that results cannot be generalised. However findings may be transferable to other populations of nursing specific or tertiary students more generally. Self-report, survey data was used to capture qualitative responses which limited the ability to seek clarification from participants or undertake memberchecking. Interviews may have captured thicker, richer data. Finally, participation and responses may have been influenced by volunteer and social desirability bias which is a limitation of the study.

\section{Conclusion}

This study explored motivators for participation in tailored MHFA training for undergraduate nursing students. The findings highlight the interrelationship between intrinsic and extrinsic motivators with key themes of mental health literacy, career, helping others and personal experience emerging. These findings suggest while intrinsic motivation is important to generate initial interest in completing the MHFA course, extrinsic motivators, especially related to the desire to help others are important in course completion. The prevalence of mental health problems among university students make these motivators very salient. Tertiary institutions would benefit from policy to embed MHFA training into nursing programs to complement existing course material which may also demonstrate utility in other degrees.

\section{Abbreviation \\ MHFA: Mental Health First Aid}

\section{Acknowledgements}

We would like to acknowledge Kristen Hunt, Dr. Jonathan Hallett, Dr. Hui Jun Chih and P.J. Matt Tilley in the project development and implementation.

We appreciate the support of the Schools of Public Health and Nursing and Midwifery and the contribution of all participants. Thanks to Indah

Mohamed-Isa for her assistance with data analysis for this project.

\section{Authors' contributions}

SB and GC conducted the data analysis for this paper. GC and SB drafted the manuscript and both authors read, edited and provided critical feedback on the final manuscript and approved it for publication.

\section{Authors' information}

GC has experience in mental health research and practice and is an accredited Master Mental Health Aid trainer. SB is an experienced researcher and practitioner in mental health, particularly in the area of mental health promotion with young people.

\section{Funding}

This project was funded in part by the School of Public Health, Curtin University.

Availability of data and materials

The datasets used and/or analysed during the current study are available from the corresponding author on reasonable request.

\section{Ethics approval and consent to participate}

Ethical approval for this study was granted by the Curtin University Human Research Ethics Committee (Approval number: SPH-74-2013). Participants provided written consent when they checked the box to complete the baseline survey.

\section{Consent for publication}

Not applicable.

\section{Competing interests}

The authors declare that they have no competing interests.

Received: 18 January 2018 Accepted: 24 February 2020

Published online: 06 March 2020

\section{References}

1. Australian Bureau of Statistics. National Survey of mental health and wellbeing: summary of results. Canberra: Australian Bureau of Statistics; 2008. 
2. Alonso J, Angermeyer MC, Bernert S, Bruffaerts R, Brugha TS, Bryson $\mathrm{H}$, et al. Disability and quality of life impact of mental disorders in Europe: results from the European study of the epidemiology of mental disorders (ESEMeD) project. Acta Psychiatr Scand Suppl. 2004;420:38-46.

3. Burgess PM, Pirkis JE, Slade TN, Johnston AK, Meadows GN, Gunn JM. Service use for mental health problems: findings from the 2007 National Survey of mental health and wellbeing. Aust N Z J Psychiatry. 2009;43(7): 615-23.

4. Jorm AF. Mental health literacy: empowering the community to take action for better mental health. Am Psychol. 2012;67(3):231-43.

5. Jorm AF. Mental health literacy: public knowledge and beliefs about mental disorders. Br J Psychiatry. 2000;177(1):396-401.

6. Jorm AF, Barney LJ, Christensen H, Highet NJ, Kelly CM, Kitchener BA. Research on mental health literacy: what we know and what we still need to know. Aust N Z J Psychiatry. 2006a;40(1):3-5.

7. Terry J. Experiences of instructors delivering the mental health first aid training programme: a descriptive qualitative study. J Psychiatr Ment Health Nurs. 2010;17(7):594-602.

8. Jorm AF, Kelly CM, Wright A, Parslow RA, Harris MG, McGorry PD. Belief in dealing with depression alone: results from community surveys of adolescents and adults. J Affect Disord. 2006;96(1-2):59-65.

9. Kelly CM, Mithen JM, Fischer JA, Kitchener BA, Jorm AF, Lowe A, et al. Youth mental health first aid: a description of the program and an initial evaluation. Int J Ment Heal Syst. 2011;5(1):4.

10. Kitchener BA, Jorm AF. Mental health first aid training: review of evaluation studies. Aust N Z J Psychiatry. 2006;40(1):6-8.

11. Mendenhall AN. Predictors of service utilization among youth diagnosed with mood disorders. J Child Fam Stud. 2012;21(4):603-11.

12. Kessler RC, Foster CL, Saunders WB, Stang PE. Social consequences of psychiatric disorders. I: Educational attainment Am J Psychiatry. 1995;152(7): 1026-32.

13. O'Brien AP, Cho MAA, Lew AM, Creedy D. Ho Chun man R, Chan MF, Gordon Arthur D. the need for mental health promotion and early intervention Services for Higher Education Students in Singapore. Int J Ment Health Promot. 2010;10(3):42-8.

14. Reavley NJ, Jorm AF. Prevention and early intervention to improve mental health in higher education students: a review. Early Interv Psychiatry. 2010; 4(2):132-42.

15. Shuchman M. Falling through the cracks-Virginia Tech and the restructuring of college mental health services. N Engl J Med. 2007:357(2):105-10.

16. Cretkovski S, Reavley NJ, Jorm AF. The prevalence and correlates of psychological distress in Australian tertiary students compared to their community peers. Aust N Z J Psychiatry. 2012;45(6):457-67.

17. Hunt J, Eisenberg D. Mental health problems and help-seeking behavior among college students. J Adolesc Health. 2010;46(1):3-10.

18. Leahy CM, Peterson RF, Wilson IG, Newbury JW, Tonkin AL, Turnbull D. Distress levels and self-reported treatment rates for medicine, law, psychology and mechanical engineering tertiary students: Cross-sectional study. Aust N Z J Psychiatry. 2010;44(7):608-15.

19. Stallman HM. Psychological distress in university students: a comparison with general population data. Aust Psychol. 2010;45(4):249-57.

20. Rickwood DJ, Deane FP, Wilson CJ. When and how do young people seek professional help for mental health problems? Med J Aust. 2007;187(7 Suppl):S35-9.

21. Reavley NJ, McCann TV, Jorm AF. Actions taken to deal with mental health problems in Australian higher education students. Early Interv Psychiatry. 2012;6(2):159-65.

22. Andrews B, Wilding JM. The relation of depression and anxiety to life-stress and achievement in students. Br J Psychol. 2004;95(1):509-21.

23. Arria AM, Caldeira KM, Vincent KB, Winick ER, Baron RA, O'Grady KE. Discontinuous college enrollment: associations with substance use and mental health. Psychiatr Serv. 2013;64(2):165-72.

24. James $\mathrm{R}$, Krause $\mathrm{KL}$, Jennings $\mathrm{C}$. The first year experience in Australian universities: findings from 1994-2009: Centre for the Study of Higher Education, University of Melbourne; 2010.

25. Lipson SK, Eisenberg D. Mental health and academic attitudes and expectations in university populations: results from the healthy minds study. J Ment Health. 2018;27(3):205-13.

26. Bewick B, Koutsopoulou G, Miles J, Slaa E, Barkham M. Changes in undergraduate students' psychological well-being as they progress through university. Stud High Educ. 2010;35(6):633-45.
27. Bond KS, Jorm AF, Kitchener BA, Reavley NJ. Mental health first aid training for Australian medical and nursing students: an evaluation study. BMC Psychol. 2015;3(1):11.

28. Crawford G, Burns S, Chih J, Hunt K, Tilley M, Hallett J, et al. Mental health first aid training for nursing students: a protocol for a pragmatic randomised controlled trial. BMC Psychiatry. 2015;15:26.

29. Bovopoulos N, Kelly C, Bond KS, Kitchener BA. Mental health first aid: supplementary booklet for nursing students. Melbourne: Mental Health First Aid Australia; 2013.

30. Pulido-Martos M, Augusto-Landa JM, Lopez-Zafra E. Sources of stress in nursing students: a systematic review of quantitative studies. Int Nurs Rev. 2012;59(1):15-25.

31. Reeve KL, Shumaker CJ, Yearwood EL, Crowell NA, Riley JB. Perceived stress and social support in undergraduate nursing students' educational experiences. Nurse Educ Today. 2013;33(4):419-24.

32. Rella S, Winwood PC, Lushington $\mathrm{K}$. When does nursing burnout begin? An investigation of the fatigue experience of Australian nursing students. J Nurs Manag. 2009;17(7):886-97.

33. Evans W, Kelly B. Pre-registration diploma student nurse stress and coping measures. Nurse Educ Today. 2004;24(6):473-82.

34. McCann TV, Lu S, Berryman C. Mental health literacy of Australian bachelor of nursing students: a longitudinal study. J Psychiatr Ment Health Nurs. 2009;16(1):61-7.

35. Happell B, Gaskin CJ. The attitudes of undergraduate nursing students towards mental health nursing: a systematic review. J Clin Nurs. 2013;22(12):148-58.

36. Australian Institute of Health and Welfare. Nursing and midwifery workforce 2011. Canberra: Australian Institute of Health and Welfare; 2012.

37. Australian Institute of Health and Welfare. Mental health services-in brief 2015. Canberra: Australian Institute of Health and Welfare: 2015.

38. Productivity Commission. Australia's health workforce, research report. Canberra: Australian Government; 2005

39. Jorm AF, Kitchener BA. Noting a landmark achievement: mental health first aid training reaches $1 \%$ of Australian adults. Aust N Z J Psychiatry. 2011; 45(10):808-13.

40. Jensen KB, Morthorst BR, Vendsborg PB, Hjorthoj CR, Nordentoft M. The effect of the mental health first-aid training course offered employees in Denmark: study protocol for a randomized waitlist-controlled superiority trial mixed with a qualitative study. BMC Psychiatry. 2015;15:80.

41. Zilnyk A. Mental health first aid-a life skill we should all have? Perspect Public Health. 2010;130(2):61-2.

42. Hadlaczky G, Hokby S, Mkrtchian A, Carli V, Wasserman D. Mental health first aid is an effective public health intervention for improving knowledge, attitudes, and behaviour: a meta-analysis. Int Rev Psychiatry. 2014;26(4):467-75.

43. Jorm AF, Kitchener BA, Fischer JA, Cvetkovski S. Mental health first aid training by e-learning: a randomized controlled trial. Aust N Z J Psychiatry. 2010;44(12):1072-81.

44. Jorm AF, Kitchener BA, Sawyer MG, Scales H, Cvetkovski S. Mental health first aid training for high school teachers: a cluster randomized trial. BMC Psychiatry. 2010;10:51.

45. Kelly J, Birks M. 'It's the simple things you do first that start the process of help': undergraduate nursing and midwifery students' experiences of the mental health first aid course. Collegian. 2017;24(3):275-80.

46. Kitchener BA, Jorm AF. Mental health first aid training for the public evaluation of effects on knowledge, attitudes and helping behavior. BMC Psychiatry. 2002;2:10.

47. O'Reilly CL, Bell JS, Kelly PJ, Chen TF. Impact of mental health first aid training on pharmacy students' knowledge, attitudes and self-reported behaviour: a controlled trial. Aust N Z J Psychiatry. 2011:45(7):549-57.

48. Morawska A, Fletcher R, Pope S, Heathwood E, Anderson E, McAuliffe C Evaluation of mental health first aid training in a diverse community setting. Int J Ment Health Nurs. 2013;22(1):85-92.

49. Jorm AF, Kitchener BA, O'Kearney R, Dear K. Mental health first aid training of the public in a rural area: a cluster randomized trial. BMC Psychiatry. 2004:4:33.

50. Kitchener BA, Jorm AF. Mental health first aid training in a workplace setting: a randomized controlled trial. BMC Psychiatry. 2004;4:23.

51. Jorm AF, Kitchener BA, Mugford SK. Experiences in applying skills learned in a mental health first aid training course: a qualitative study of participants stories. BMC Psychiatry. 2005;5:43. 
52. Mental Health First Aid Australia. Nd. Standard MHFA for Nursing Students Retrieved from https://mhfa.com.au/courses/public/types/tailorednursing. Accessed 12 August 2017.

53. Nilsson KEL, Stomberg MIW. Nursing students' motivation toward their studies - a survey study. BMC Nurs. 2008;7(1):1-7.

54. Ryan RM, Deci EL. Self-determination theory and the facilitation of intrinsic motivation, social development, and well-being. Am Psychol. 2000;55(1):68-78.

55. Miller KL. Motivating factors and barriers for faculty online professional development. (3701019 Ed.D.). Ann Arbor: Morehead State University; 2015.

56. de Bilde J, Vansteenkiste $M$, Lens $\mathbf{W}$. Understanding the association between future time perspective and self-regulated learning through the lens of self-determination theory. Learn Instr. 2011;21(3):332-44.

57. Lee J, Turner J. The role of pre-service teachers' perceived instrumentality, goal commitment, and motivation in their self-regulation strategies for learning in teacher education courses. Asia Pac J Teach Educ. 2016:1-16.

58. Happell B, Wilson R, McNamara P. Undergraduate mental health nursing education in Australia: more than mental health first aid. Collegian. 2014; 22(4):433-8

59. Kitchener BA, Jorm AF. The role of mental health first aid training in nursing education: a response to Happell, Wilson \& McNamara (2015). Collegian. 2017;24(3):313-5.

60. Burns S, Crawford G, Hallett J, Hunt K, Chih HJ, Tilley PJM. What's wrong with John? A randomised controlled trial of mental health first aid (MHFA) training with nursing students. BMC Psychiatry. 2017;17(1):111.

61. Yap MB, Wright A, Jorm AF. Young people's mental health first aid intentions and beliefs prospectively predict their actions: findings from an Australian National Survey of youth. Psychiatry Res. 2012;196(2-3):315-9.

62. Yap MB, Wright A, Jorm AF. First aid actions taken by young people for mental health problems in a close friend or family member: findings from an Australian national survey of youth. Psychiatry Res. 2011;188(1):123-8.

63. Sartore GM, Kelly B, Stain HJ, Fuller J, Fragar L, Tonna A. Improving mental health capacity in rural communities: mental health first aid delivery in drought-affected rural New South Wales. Aust J Rural Health. 2008;16(5): 313-8.

64. Terry J. Mental health first aid - rolling out across the UK. J Public Ment Health. 2009;8(3):33-7.

65. IBM Corporation. IBM SPSS statistics for windows (version 22). Armonk, NY: IBM Corp; released; 2013

66. Braun V, Clarke V. Using thematic analysis in psychology. Qual Res Psychol. 2006:3:77-101.

67. Burns S, Bowser N, Smith J, Jancey J, Crawford G. An exploratory study of smokers' and stakeholders' expectations of the implementation of a smokefree policy in a university setting. Health Promot J Austr. 2014;25(2):129-35.

68. Denehy M, Crawford G, Leavy J, Nimmo L, Jancey J. Formative research to develop theory-based messages for a Western Australian child drowning prevention television campaign: study protocol. BMJ Open. 2016;6:e010033. https://doi.org/10.1136/bmjopen-2015-010033.

69. Jones C, Burns S, Howat P, Jancey J, McManus A, Carter O. Playgroups as a setting for nutrition and physical activity interventions for mothers with young children: exploratory qualitative findings. Health Promot J Austr. 2010;21(2):92-8.

70. Reilly T, Crawford G, Lobo R, Leavy J, Jancey J. Ethics and health promotion practice: exploring attitudes and practices in Western Australian health organisations. Health Promot J Austr. 2016;27(1):54-60.

71. Liamputtong P. The science of words and the science of numbers. In: Liamputtong $P$, editor. Research method in health: foundations for evidence-based practice. South Melbourne: Oxford; 2013.

72. NVivo qualitative data analysis Software (Version 11). QSR International Pty Ltd; 2015.

73. Davies B, Beever E, Glazebrook C. The mental health first aid eLearning course for medical students: a pilot evaluation study. Europe Health Psych. 2016;18(S):1.

74. Lipson SK, Speer N, Brunwasser S, Hahn E, Eisenberg D. Gatekeeper training and access to mental health Care at Universities and Colleges. J Adolesc Health. 2014;55(5):612-9.

75. Svensson B, Hansson L. Effectiveness of mental health first aid training in Sweden. A randomized controlled trial with a six-month and two-year follow-up. PLoS One. 2014;9(6):e100911.

76. Byrne K, McGowan I, Cousins W. Delivering mental health first aid: an exploration of instructors' views. Int J Ment Health Promot. 2015;17(1):3-21.
77. Murphy C, Cross C, McGuire D. The motivation of nurses to participate in continuing professional education in Ireland. JEIT. 2006;30(5):365-84.

78. Barriball KL, While AE. Participation in continuing professional education in nursing: findings of an interview study. J Adv Nurs. 1996;23(5):999-1007.

79. Waddell D. Why do nurses participate in continuing education? A metaanalysis. J Contin Educ Nurs. 1993;24(2):52-6.

80. Kristjanson LSJ. Assessment of continuing nursing education needs: a literature review. J Contin Educ Nurs. 1989;20(3):118-23.

81. O'Connor AB. Reasons nurses participate in continuing education. Nurs Res. 1979;28(6):354-9.

82. Mathieu JE, Martineau JW. Individual and situational influences on training motivation. In ford SWK, Kraiger K, Salas E, Teachout MS (Ed.), improving training effectiveness in work organizations (pp. 193-221). Mahwah: Lawrence Erlbaum Associates; 1997.

83. Grant AM. Does intrinsic motivation fuel the Prosocial fire? Motivational synergy in predicting persistence, performance, and productivity. J Appl Psychol. 2008;93(1):48-58.

84. Weinberg R, Gould D. Foundations of sport and exercise psychology. Champaign: Human Kinetics; 2003.

85. Health Workforce Australia. Australia's health workforce series - nurses in focus. Adelaide: Department of Health; 2013.

\section{Publisher's Note}

Springer Nature remains neutral with regard to jurisdictional claims in published maps and institutional affiliations.
Ready to submit your research? Choose BMC and benefit from:

- fast, convenient online submission

- thorough peer review by experienced researchers in your field

- rapid publication on acceptance

- support for research data, including large and complex data types

- gold Open Access which fosters wider collaboration and increased citations

- maximum visibility for your research: over 100M website views per year

At BMC, research is always in progress.

Learn more biomedcentral.com/submissions 